\title{
EMPRESARIALES
}

\section{Las condiciones de trabajo desde la perspectiva del trabajo decente en la Ciudad de Concepción, Paraguay}

\author{
Ángela Edda Lizts Navarro Garay
}

\begin{abstract}
Resumen
Introducción: Según la Declaración de la Organización Internacional del Trabajo (OIT), "el trabajo decente sintetiza las aspiraciones de las personas durante su vida laboral, significa la oportunidad de acceder a un empleo productivo que genere un ingreso justo, la seguridad en el lugar de trabajo y la protección social para las familias, mejores perspectivas de desarrollo personal e integración social, libertad para que los individuos expresen sus opiniones, se organicen y participen en las decisiones que afectan sus vidas, y la igualdad de oportunidades y trato para todos, mujeres y hombres". En este trabajo se presenta una descripción de la situación laboral de los trabajadores en la ciudad de Concepción, Paraguay a partir del paradigma del trabajo decente, abordando un eje estratégico del modelo: los derechos en el trabajo.

Objetivo: Se estableció como objetivo describir las condiciones de trabajo mediante una aproximación a la situación laboral de los trabajadores en la ciudad de Concepción
\end{abstract}

Material y Método: El método utilizado en este trabajo fue el de aplicar un cuestionario a un grupo heterogéneo de 300 trabajadores en diversos sectores con el fin de emitir una descripción más aproximada a la realidad, aplicando un enfoque cuantitativo de tipo descriptivo, mediante información de fuente primaria, se complementó la información con fuentes secundarias consistentes en trabajo de investigación de campo de otros investigadores locales y revisión bibliográfica sobre el tema de estudio.

Resultados: La mayoría de los trabajadores se emplean en el sector comercial, laboran más de 8 horas por día, en promedio se observa una antigüedad menor a 5 años, perciben mayoritariamente entre mínimo y menos del mínimo, 50,9\% no posee contrato laboral por escrito, en cuanto al usufructo de las vacaciones pagadas, un poco más de la mitad manifestó que la empresa le concede el derecho de vacaciones, sin embargo, los que perciben remuneraciones como comisionistas no gozan de este beneficio. En cuanto a la tenencia del seguro

1. Universidad Nacional de Concepción. Facultad de Ciencias Económicas y Administrativas. Este trabajo fue presentado en el I Seminario de Investigación en Ciencias Sociales CLACSO. E-mail: anavarro53@hotmail.com

DOI: 10.26885/rcei.foro.2018.88 
social del IPS, la mayoría admitió no estar asegurado así como tampoco cuentan con seguros médicos privados, sobre el reconocimiento de la antigüedad en el trabajo menos de la mitad manifestó creer que la empresa le reconoce su antigüedad mientras que la mayoría se declara incrédulo al respecto.

Conclusiones: Los datos aquí presentados muestran que en el departamento de Concepción las condiciones laborales distan del ideal y no puede considerarse la adopción del paradigma de Trabajo Decente ya que existe incumplimiento a las leyes que protegen los derechos del trabajador, precariedad en ciertos sectores y desinformación por parte de los propios trabajadores, se nota que quienes más lejos del modelo se encuentran son los trabajadores que laboran en el sector comercial, los que trabajan en la zona rural así como los que laboran en el sector farmacéutico y minería. En cuanto al diálogo social este aún no ha iniciado en la ciudad ya que en el sector privado no se observa la presencia de sindicatos locales.

Palabras clave: trabajo decente, condiciones de trabajo, derechos en el trabajo.

\section{RefEREnCias}

Ayala, D. (s.f.). Ocupación Informal en Paraguay. Evolución, Características y Acciones de Políticas Públicas. Observatorio Laboral. Publicación del Ministerio de Trabajo, Empleo y Seguridad Social. Recuperado de www. sinafocal.gov.py

Benítez, L., Escobar, N. (2014). Explotación Minera en las canteras de mármol y otros calcáreos del Cerro Tigre, distrito de San Lázaro, Concepción. Universidad Nacional de Concepción.

Ghai, D. (2003). Trabajo decente. Concepto e indicadores. Revista Internacional del Trabajo, 122(2).

Lachi, M. (2011). Condicionantes Político-Institucionales del Trabajo Decente en Paraguay. Documentos de Trabajo. Germinal. Publicación Periódica de Análisis y Estudios sobre la Realidad Social y Política del Paraguay. Asunción: Centro de Estudios y Educación Popular Germinal.

OIT. (2013). Situación del Trabajo Decente en México. Boletín Semestral, $1(1)$.

OIT-PNUD. (2013). Informe Nacional sobre Desarrollo Humano Paraguay 2013. Trabajo Decente y Desarrollo Humano. Asunción, Paraguay. 